\title{
PENGARUH UMPAN ASLI DAN UMPAN BUATAN DENGAN WAKTU PENANGKAPAN YANG BERBEDA PADA ALAT TANGKAP PANCING TANGAN (HAND LINE) TERHADAP JUMLAH DAN JENIS IKAN DI PERAIRAN TELUK MAUMERE
}

\author{
Erfin \\ Universitas Nusa Nipa, Maumere, laerfin@gmail.com
}

https://doi.org/10.31943/gemawiralodra.Vol9.Iss2.346

\begin{abstract}
ABSTRAK
Penelitian ini bertujuan untutk mengetahui pengaruh penggunaan dua jenis perilakuan yaitu Umpan Asli (cumi-cumi) dn umpn buatan ( karet ventil) dengan perbedaan waktu penangkapan terhadap jumlah dan hasil tangkapan ikan dengan menggunakan alat tangkap pancing tangan (hand line) di perairan teluk Maumere Kabupaten Sikka. Metode yang digunakan dalam penelitian ini adalah metode eksperimen di mana peneliti terlibat secara langsung dalam operasi penangkapan dengan alat tangkap pancing tangan (hand line) dengan melakukan penangkapan masing-masing dua faktor yaitu kedua adalah perbedaan waktu penangkapan (pagi, siang, dan malam hari). Dari kedua perlakuan, maka hasil tangkapan yang diperoleh dalam operasi penngapan pancing tangan (hand line) yaitu, pertama, menggunakan perbedaan umpan asli (cumi-cumi) dan umpan buatan (karet ventil). Sedangkan faktor pada perlakuan dan ulangan yang menggunakan umpan asli (cumi-cumi) didapat hasil tangkapan sebanayak 321 ekor dengan rata-rata 107. Sedangkan mengguanakan umpan buat (karet ventil) didapat hasil tangkapan sebanayak 293 ekor dengn rata-rata 97,67. Dari hsil pengujian hipotesis didapatkan bahwa Fatbel taraf nyata 0,05 dan 0,01 menujukan hasil nyata atau $\mathrm{F}_{\text {hitung }}=3,477>\mathrm{F}_{\text {tabel }}>(0,05)$. Maka tolak $\mathrm{H}_{0}$ diterima dengan $\mathrm{H}_{1}$ dengan hasil nyata singnifikan. Jadi adanya pengaruh umpan terhadap hasil tangkapan. Maka selanjutnya akan di hitung manggunakan Uji Beda Nyata Jujur (BNJ). Pada Uji BNJ, Didapat hasil tangkapan hasil tertinggi dari perlakuan A3B1 yaitu mengguanakan umpan asli (cumi-cumi) pada waktu penangkapan malam hari. Kesimpulan yang didapat dari penelitian ini adalah perlakuan kombinasi yang memeberikan hasil tangkapan terbanyak adalah perlakuan kimbinasi A3B1 yang berbeda nyata dengan perlakuan kombinasi lainya.
\end{abstract}

\section{Kata Kunci : Pancing Tangan, Ikan, Maumere}

\begin{abstract}
This research has been carried out on stairs 01 to samapai 30 july 2015 in wailiti urban village. The purpose of this research is to know the effect of the use of two kinds of treatments, namely the Original Feed (squid) and artificial rubber (rubber ventil) with the difference of time of catching the number and yield of the fish by using the fishing gear (hand line) in the waters of Teluk maumere sikka. The method used in this research is an experimental method in which the researcher is directly involved in the operation of catching with the fishing gear (hand line) by catching each of the two factors namely first, using the original feed difference (squid) and artificial feed (rubber vents). While the second factor is the difference of arrest wktu (morning, afternoon, and night). Of the two treatments, the catches obtained in the hand-fishing line operation, ie, in the treatment and replication that used the original uma (squid), obtained by catching sebanayak 321 fish with an average of 107 . While mengguanakan bait making ( rubber ventil) obtained the catch sebanayak 293 tails with an average of 97.67. From the result of hypothesis testing, it was found that Fatbel real level of 0.05 and 0.01 showed the real result or $\mathrm{F}_{\text {count }}=3,477>\mathrm{F}_{\text {tabel }}>(0,05)$. Then reject $\mathrm{H}_{0}$ is received with $\mathrm{H}_{1}$ with significant result. So the influence of the bait on the catch. Then the next will be calculated manggunakan Test Differences Honest (BNJ). At the BNJ Test, the highest yield of the A3B1 treatment was obtained by using original feed (squid) at night time capture.The conclusion obtained from this research is the treatment of kmbinasi which gives the best catch is the treatment of kimbinasi A3B1 which is significantly different from the other combination treatment
\end{abstract}


Keyword(s): Hand Line, Fish, Maumere

\section{PENDAHULUAN}

Penangkapan ikan merupakan salah satu usaha di bidang perikanan, baik itu penangkapan ikan di laut, danau maupun sungai. Usaha penangkapan ikan membutuhkan suatu alat tangkap, yang salah satunya adalah pancing tangan (hand line) yang digunakan oleh nelayan di perairan teluk maumere. Pancing tangan (hand line) yang dioperasikan dengan cara dan konstruksi yang berbeda diharapkan dapat efektif untuk mendapatkan hasil tangkapan yang banyak. Penggunaan umpan yang berbeda juga disesuaikan dengan kondisi di perairan teluk maumere.

Nelayan di perairan teluk maumere yang mengoperasikan pancing tangan (hand line) umumnya menggunakan jenis umpan asli sehingga dalam penelitian digunakan jenis umpan asli dan buatan. Menurut Brandt (1984) (Ardhya, 2010) umpan pada umumnya digunakan sebagai alat bantu penangkapan karena memberikan rangsangan yang dapat diterima oleh reseptor pada ikan, yaitu penglihatan dan penciuman, diterimanya rangsangan dari umpan terhadap penglihatan dan penciuman yang merupakan bagian paling penting untuk mencari makan. Penggunaan umpan pada suatu pengoperasian alat tangkap berfungsi untuk mengundang atau merangsang ikan sehingga sistem pengoperasian yang dilakukan akan lebih efektif.

Kabupaten Sikka adalah salah satu wilayah administrasi yang ada di propinsi Nusa Tenggara Timur (NTT). Potensi kelautan dan perikanan dikabupaten Sikka sangat menjanjikan untuk perkembangan ekonomi. Dari besarnya kekayaaan laut Flores, semuanya belum secara optimnal karena keterbatasan sarana dan prasarana sumberdaya manusia. Masih bayak masyarakat Flores yang hidup dibawah garis kemiskinan dan masih banyak terimajinalisasi (keterbelakangan), dalam hal karena perkembanggan teknologi moderen. Salah satu potensi ikan di Kabupaten Sikka yang banyak dipasaran adalah jenis ikan pelagis dan demersal yang usaha penangkapanya dengan mengguanakan bermacammacam alat tangkap salah satunya adalah pancingan tangan (hand liene). Hand line adalah jenis alat penangkapan yang terdiri dari seutas tali utama dengan pemberat dan sejumlah tali cabang (Sudirman dan Malawa, 2002). Di perairan Teluk Maumere pengoprasiuan alat tanggkap tangan (hand line) banyak digunakan untuk menangkap ikan - ikan pelagis dan demersal yang hidup di perairan dasar, Pertengahan dan belakang yang mempunyai nilai ekonomis penting (Ayodhyoa,1979). 


\section{METODE PENELITIAN}

Metode yang digunakan dala penelitian ini adalah metode eksperimen yaitu metode yang pada dasarnya mengadakan percoban secara langsung dalam mealakuakan peangkapan pada setiap perlakuan. Penelitian ini dianalisa dengan menggunakan percobaan rancangan factorial yang dilaksanakan denagan Rancangan Acak Kelompok (RAK)

Perbedaan A adalah perbedaan waktu peanagkapan. Perlakun A1 yaitu operasi penangkapan pada pagi hari. Perlakuan A2 yaitu opersi penangkapan pada siang hari dan Peralakuan A3 yaitu operasi penangkapan pada malam hari.

Perbedaan B adalah perbedaaan umpan asli dan uampan buatan, perlakuan B1 yaitu mengguankan umpan asli (cumi-cumi) dan perlakuan B2 yaitu mengguanakan umpan (karet ventil).

Sehingga akan di peroleh kombinasi perlakuan sebanyak 6 (enam) macam yaitu
1. A1B1
3. $\mathrm{A} 2 \mathrm{~B} 1$
5. A3B1
2. A1B2
4. $\mathrm{A} 2 \mathrm{~B} 2$
6. A3B2

Hal ini sesuai dengan hubungan perlakuan dengan ulangan dapat ditentukan sebagai berikut $(\mathrm{t}-1)(\mathrm{n}-1) \geq 15$

Diamana : $\mathrm{t}$ : banyaknya perlakuan

$\mathrm{n}$ : banyaknya ulangan

dari hasil perhitungan tersebut dimasukan dalam tabel sidik ragam (ANOVA)

\section{Prosedur Penelitian}

1. Persiapan Alat dan Bahan

Menentukan dan menyiapkan sarana penangkapan secara keseluruan sebelum menuju lokasi penangkapan (fishing ground)

2. Persiapan Umpan

Sebelum menuju lokasi penangkapan , mula-mula jenis perlakian (cumi-cumi dan karet ventil) sudah disiapkan yakni : mata kail kosong diapasang atau dikait pada tali senar yang telah di siapkan dan cumi-cumi dipotong-potong sebesar lidi, kemudian potongan cumi-cumi di kumpulkan atau diangkat ke tempat yang sudah disiapkan. Sedangkan karet ventil yang digunakan berwarna merah dan terlebih dahulu karet ventil dipotong panjang $5 \mathrm{~cm}$ dan salah satu ujungnya dipotong bagi dua, kemudian potongan tersebut dikumpulkan dan diangkat ke tempat yang disiapkan. 
Penelitian ini menggunakan dua jenis data yaitu, data kuantitati yaitu data yang angka-angka yang bersifat dapat dihitungdan data kualitatif yaitu data yang bukan merupakan angka - angka yang sifatnya tidak dapat di hitung

Jenis data pada penelitian ini adalah data Primer yaitu data yang diambil secara langsung dari kegiatan pengamatan. Data yang di peroleh dari observasi langsung, wawancra dan partisipasi aktif. Data sekunder data yang di peroleh dari kantor Dinas Kelautan dan Perikanan Kabupaten Sikka.

\section{HASIL DAN PEMBAHASAN}

Untuk mengetahui pengaruh perlakuan penggunaan beberapa jenis umpan terhadap hasil tangkapan maka dalam menganalisis data diguanakan Rancangan Acak Kelompok (RAK) yaitu ulangan sebagai kelompok (Sastrosupadi, 1995). Penelitian dengan 6 (enam) perlakuan dan 4 (empat) kali ulangan, maka seluruh terdapat 24 percobaan. Bila terdapat perbedaan nyata atau sangat nyata antara $\mathrm{F}$ hitung dan $\mathrm{F}$ table, maka dilakukan uji lanjut dengan mengunakan Uji Beda Nyata lanjut (BNJ). Data pengaruh perlakuan umpan disajikan pada tabel 1 .

Tabel 1. Hasil Tangkapan Pancing Tangan

\begin{tabular}{|c|c|c|c|c|c|c|c|}
\hline $\begin{array}{c}\text { Waktu } \\
\text { Penangkapan }\end{array}$ & $\begin{array}{c}\text { Pebedaan } \\
\text { Umpan }\end{array}$ & 1 & $\begin{array}{c}\text { Ulangan } \\
\text { Kelompok } \\
2 \\
\end{array}$ & & 4 & Total & $\begin{array}{l}\text { Rata- } \\
\text { Rata }\end{array}$ \\
\hline \multirow[t]{2}{*}{$\mathrm{A} 1$} & B1 & A1B1 & A1B1 & & A1B1 & TA1B1 & \\
\hline & B2 & $\mathrm{A} 1 \mathrm{~B} 2$ & $\mathrm{~A} 1 \mathrm{~B} 2$ & .............. & $\mathrm{A} 1 \mathrm{~B} 2$ & TA1B2 & \\
\hline \multirow[t]{2}{*}{ A } & B1 & $\mathrm{A} 2 \mathrm{~B} 1$ & $\mathrm{~A} 2 \mathrm{~B} 1$ & …............ & A2B1 & TA2B1 & ............... \\
\hline & B2 & $\mathrm{A} 2 \mathrm{~B} 2$ & A2B2 & .............. & A2B2 & TA2B2 & .............. \\
\hline \multirow[t]{2}{*}{ A3 } & B1 & $\mathrm{A} 3 \mathrm{~B} 1$ & A3B1 & ............... & $\mathrm{A} 3 \mathrm{~B} 1$ & TA3B1 & ................. \\
\hline & $\mathrm{B} 2$ & A3B2 & A3B2 & ............... & $\mathrm{A} 3 \mathrm{~B} 2$ & TA3B2 & ................. \\
\hline TOTAL & & $\mathrm{T} 1$ & $\mathrm{~T} 2$ & ..................... & $\mathrm{T} 4$ & $\mathrm{~T}$ & \\
\hline RATA-RATA & & $\mathrm{T} 1 / 6$ & $\mathrm{~T} 2 / 6$ & ................ & $\mathrm{T} 4 / 6$ & & \\
\hline
\end{tabular}

Perhitungan Jumlah Kuadrat

$\begin{array}{lll}\mathrm{db} \text { total } & = & \text { Banayaknya data }-1 \\ \mathrm{db} \text { Perlakuan } & = & \text { Banyaknya perlakuan }-1 \\ \mathrm{db} \text { Kelompo } & = & \text { Banyaknya kelompok }-1 \\ \mathrm{db} \text { Galat } & = & \mathrm{db} \text { total }-\mathrm{db} \text { kelompok }-\mathrm{db} \text { perlakuan }\end{array}$

Faktor Koreksi $(\underline{\mathrm{FK} \quad})=(\mathrm{T})^{2}$

$$
(\mathrm{a} \times \mathrm{b} \mathrm{n})
$$

JK Total $(\mathrm{JKT})=\left(1 \mathrm{~A}_{1} \mathrm{~B}_{1}\right)^{2}+\left(2 \mathrm{~A}_{1} \mathrm{~B}_{1}\right)^{2}+\ldots .+\left(4 \mathrm{~A}_{1} \mathrm{~B}_{1}\right)^{2}-\mathrm{FK}$

JK Perlakuan (JKP)

$=\underline{\left(\mathrm{TA}_{1} \mathrm{~B}_{1}\right)^{2}+\left(\mathrm{TA}_{1} \mathrm{~B}_{2}\right)^{2}+\ldots+\left(\mathrm{TA}_{1} \mathrm{~B}_{1}\right)^{2}-\mathrm{FK}}$ 


\section{$\mathrm{a} \times \mathrm{b}$}

JK Kelompok (JKK)

$$
=\frac{\left(\mathrm{T}_{1}\right)^{2}+\left(\mathrm{T}_{2}\right)^{2}+\ldots .+\left(\mathrm{T}_{4}\right)^{2}-\mathrm{FK}}{\mathrm{a} \times \mathrm{b}}
$$

JK Galat $(\mathrm{JKG}) \quad=\mathrm{JKT}-\mathrm{JKP}-\mathrm{JKK}$

KT Perlakuan $($ KTP $)=$ JK Perlakuan

db Perlakuan

KT Kelompok $(\mathrm{KTK})=$ JK Kelompok

$$
\overline{\mathrm{db} \text { Kelompok }}
$$

KT Galat $($ KTG $)=\frac{\text { JK Galat }}{\text { db Galat }}$

F hitung perlakuan $\quad=\quad$ KT Perlakuan

$$
\text { KT Galat }
$$

F hitung kelompok $\quad=\quad$ KT Kelompok

$$
\text { KT Galat }
$$

Keterangan :

$\mathrm{a}=$ jumlah perlakun umpan

$\mathrm{b}=$ Jumlah perlakuan waktu pancing

$\mathrm{n}=$ Jumlah ulang

$\mathrm{t}$ = Banyaknya Kelompok

Kemudian Jk perlakuan diuraikan menjadi JK perbedaan umpan asli (A), JK Waktu penangkapan (B) dan JK interaksi pancingan JK waktu pancingan ( A x B ). Untuk melihat jumlah kuadrat dapat dilihat pada tabel 2.

Tabel 2 Perlakuan Beda Waktu Penangkapan dan Umpan

\begin{tabular}{cccc}
\hline Beda Waktu & Beda & Umpan & Total \\
\cline { 2 - 3 } Penangkapan & & & \\
\hline & B1 & B2 & \\
A1 & A1B1 & A1B2 & TA1 \\
A2 & A2B1 & A2B2 & TA2 \\
A3 & A3B1 & A3B2 & TA3 \\
& TB1 & TB2 & \\
\hline
\end{tabular}




$$
\mathrm{JK}(\mathrm{A})=\frac{\left(\mathrm{TA}_{1}\right)^{2}+\left(\mathrm{TA}_{2}\right)^{2}+\left(\mathrm{TA}_{3}\right)^{2}-\mathrm{FK}}{\mathrm{B} \times \mathrm{n}}
$$

$$
\mathrm{JK}=\frac{\left(\mathrm{TB}_{1}\right)^{2}+\left(\mathrm{TB}_{2}\right)^{2}+\left(\mathrm{TB}_{3}\right)^{2}-\mathrm{FK}}{\mathrm{ax} \mathrm{n}}
$$

$\mathrm{Jk}(\mathrm{A}) .(\mathrm{B}) \quad=\mathrm{Jk}$ perlakuan $-\mathrm{Jk}(\mathrm{A})-\mathrm{Jk}(\mathrm{B})$

Pada penelitian ini alat tangkap yang digunakan adalah alat tangkap pancing tangan (hand line), sejalan dengan penelitian (Susyawati,1994), bahwa kontruksi alat tangkap pancing tangan hand line adalah sebagai berikut

\section{Close stik}

Close stik yang digunakan adalah yang terbuat dari bambu yang terbuat dari bambu yang berfungsi sebagai tempat menggulungkan senar atau tali pancing.

\section{Tali pancing}

Tali pancing yang digunakan adalah senar dengan ukuran tali pancing inti nomor 200 dan tali pancing cabang nomor 80 dengan 10-50 meter.

\section{Swivel (kili-kili)}

Swivel adalah logam yang terbuat sedemikian rupa berbentuk kecil, bahanya terbuta dari kuningan, gunanya untuk menghubungkan tali pancing ke tali yang lain atau kawat baja yang berfungsi sebagai poros putar agar tidak mempengaruhi tali yang lain atau putaran tali cabang yang disebabkan oleh gerakan-gerakan ikan yang tertangkap sehingga tali utama tidak memutar (main line).

\section{Hook (mata pancing)}

Mata pancing terbuat dari kawat baja dan pada ujung mata pancing berkait balik. Sedangkan nomor mata pancing yang digunakan adalah nomor 17. Satu unit alat tangkap, dipasang 10 cabang untuk mata pancing dengan jarak antara yang satu dengan yang lain adalah satu dengan yang lain adalah $50 \mathrm{~cm}$ dan panjang tali cabang untuk pancing $15 \mathrm{~cm}$.

\section{Pemberat}

Pemberat yang digunakan adalah dari timah yang berfungsi untuk mepercepat tenggelamnya umpan dan juga untuk menjaga agar posisi alat tangkap tetap tegak lurus dan tidak mudah dibawah arus.

\section{Umpan}

Umpan ynag digunakan harus dapat membuat ikan agar terkait pada mata pancing. Terkaitnya ikan ini dikarenakan ransangan berupa bau, bentuk, dan warna umpan yang digunakan, (Sudirman dan Malawa 2000). Dalam penelitian ini umpan yang digunakan 
ada 2 jenis yaitu dengan menggunakan umpan asli berupa cumi-cumi dan menggunkan umpan buatan berupa karet ventil berwarna merah. Dengan 2 jenis umpan tersebut, dapat dioperasikan secara bersamaan selama waktu yang ditentukan. Dari kedua jenis umpan tersebut, yang dapat membedakan adalah bentuk, warna, dan rasa yang dapat merangsang ketertarikan ikan.

1. Umpan cumi-cumi

Sebelum umpan cumi-cumi dikaitkan atau dipasang pada mata kail, terlebih dahulu umpan tersebut dipotong-potong sebesar lidi dengan panjangnya $5 \mathrm{~cm}$. Kemudian potongan cumi-cumi tersebut diangkat satu persatu, lalu di pasang atau dikaitkan pada mata kail yang telah disiapkan sampai ke sepuluh mata kail (10 tali cabang). Umpan yang digunakan yaitu umpan yng segar, berwarna terang, tidak berbau.

2. Umpan Karet Ventil

Karet ventil yang digunakan pada proses penelitian adalah yang berwarna merah. Proses pemasangan umpan karet ventil ke kail yaitu mula-mulanya dipotong terlebih dahulu dengan panjang $5 \mathrm{~cm}$ dan disalah satu ujungnya dipotong dalam bentuk renda-renda agar pada saat proses penangkapan didalam air laut (disentak-sentak), umpan tersebut terlihat adanya rumbai-rumbai yang akan merangsang apnglihatan ikan, sehingga ikan tertarik dan menyambar umpan tersebut.

Sesuai dengan hasil penelitian, bahwa dengan menggunkan 2 jenis perlakuan ternyata yang paling banyak dimakan oleh ikan adalah umpan berupa cumi-cumi yaitu selama 4 kali ulangan diantaranya, menggunakan umpan cumi-cumi sebanyak 321 ekor dan menggunakan karet ventil sebanyak 293 ekor.

\section{Rangkaian Alat Tangkap}

Pancingan tangan (hand line) yang digunakan terdiri dari beberapa bagian yakni: penggulungan atau close yang berdiameter $4 \mathrm{~cm}$, tali cabang dengan panjang $15 \mathrm{~cm}, 10 \mathrm{~cm}$ mata kail, pemberat yang terbuat dari timah, dan swivel atau kili-kili.

\section{Perahu Penangkapan}

Perahu penangkapan sangat diperlukan dalam melakukan usaha penangkapan di laut. Perahu atau kapal berfungsi sebagai sarana transportasi untuk mengantar pemancing ke daerah penangkapan (fishing ground), Karyanto (2004). Dalam penelitian ini perahu yang digunakan adalah perahu mesin tempel (out board motor) dengan kekuatan mesinnya 5 PK, panjang perahu 7 meter, lebar 2 meter, dan tinggi 1,5 meter. 


\section{Cahaya}

Cahaya merupakan gelombang yang memindahkan tenaga tanpa pembatasan massa dengan memberikan informasi yang vital tentang lingkungan kepada hewan laut (ikan). Cahaya merupakan faktor ekologi yang sangat penting bagi kehidupan biota laut karena organisme yang ada di dalam laut kuhususnya ikan, pada umumnya lebih efektif dan menunjukan sifat fototaksis yang maksimum sebelum tengah malam. Cahaya juga mempengaruhi beberapa tingkah laku ikan seperti rangsangan untuk makan dan rangsangan ikan untuk mendekati cahaya (Gunarso, 1985)

Pengaruh Perlakuan Terhadap Hasil Tangkapan

Hasil tangkapan pada alat tangkap pancing tangan yang menggunakan 3 perlakuan untuk setiap ulangan dapat dilihat pada pada tabel 3.

Tabel 3. Perhitungan Hasil Tangkapan

\begin{tabular}{ccccccc}
\hline $\begin{array}{c}\text { Faktor } \\
\text { Waktu } \\
\text { Penangkapan }\end{array}$ & Jenis & Umpan & 1 & $\begin{array}{c}\text { Ulangan } \\
\text { Kelompok }\end{array}$ & & Total \\
\hline A1 & B1 & 27 & 20 & 25 & 18 & 90 \\
& B2 & 25 & 18 & 22 & 15 & 80 \\
A2 & B1 & 28 & 22 & 24 & 29 & 103 \\
& B2 & 25 & 20 & 22 & 27 & 94 \\
A3 & B1 & 32 & 28 & 36 & 32 & 128 \\
& B2 & 30 & 25 & 34 & 30 & 119 \\
\hline Total & & 167 & 133 & 163 & 151 & 614 \\
\hline
\end{tabular}

Keterangan :

A1B1 : Waktu penangkapan pagi hari dengan menggunakan umpan cumi-cumi A1B3 : Waktu penangkapan pagi hari dengan menggunakan umpan karet ventil A2B1 : Waktu penangkapan siang hari dengan mengguanakan umpan cumi-cumi A2B2 : Waktu penangkapan siang hari dengan menggunakan umpan kateret ventil A3B1 : Waktu penangkapan malam hari dengan menggunakan umpan cumi-cumi A3B2 : Waktu penangkapan malam hari dengan menggunakan umpan karet ventil

Dari hail table tersebut, dapat dilihat bahwa jumlah hasil tangkapan ikan lebih banyak diperoleh adalah pada pancingan tangan dengan menggunakan umpan asli (cumicumi) yaitu sebanayak 321 ekor dengan rata-rata 107. Sedangkan dengan menggunakan umpan buatan (karet ventil) yaitu sebanyak 293 ekor dengan rata-rata 97,67. 
DAFTAR PUSTAKA

Anonim. 2001. Buku Pedoman Sumberdaya perikana Laut. Bagia 1 (Jenis- jenis )Ikan Ekonomis Penting). Direktorat Jemdral Perikanan Departemen Pertanian, Jakarta.

Ayodyoa. 1979. Bahan AlaT Penangkapan ikan. Jakarta: CV.Yayasan Jakarta.

Gunarso.1985. Tingkah laku Ikan dalam hubunganya dengan alat, Metode Dan Teknik Penangkapan. Fakultas Perikanan Intitusi Pertanian Bogor.

Karyanto. 2004. Modul Kapal Perikanan. Materi Penelitian Dasar Bagi Petugas. Balai Pndidikan dan Penelitian, Banyuwangi.

Sastrosupadi. 1995. Rancangan Percobaan Praktis untuk Pertani. Jogjakarta: Kanisius.

Soemarto.1982. Fishing Ground dan Sumberdaya Perikanan Tangkap. Bogor: Yayasan Dewi Sari.

Sudirman dan Mallawa. 2002. Teknik Penangkapan Ikan. Jakarta: PT. Ranika Cipta,.

Susyawati. 1994. Pengaruh Penggunaan Jenis Umpan dan Ukuran Mata Pancing Yang Berbeda Terhadap Hasil Tangkapan Pada Uji Coba Pengoperasian Rawai Dasar Bertingkat. Skripsi Penelitian Instutut Pertanian Bogor. 